\title{
Working Principle of Gas Turbine Meter Fluxi 2000/TZ and Gas Volume Converter
}

\author{
Fitria Hidayanti, Haura Ishthafayna
}

\begin{abstract}
The use of natural gas in several countries, especially in Indonesia is essential. In gas distribution, every industry and household will not be separated from the measurement system that aims to find out how much natural gas has been used. For this reason, the use of a gas flow meter is necessary. There are several types of gas flow meter can be used in measuring the gas volume. Some types of gas flow meters are gas turbine meters, rotary gas meters and diaphragm gas meters. The primary difference of each type of gas flow meter is the pressure capacity and the speed of the gas flow through it. Flow meter gas turbine is one type of gas flow rate measuring device. There are moving parts consisting of a propeller whose rotation speed is proportional to the flow rate through the flow meter. The type of gas turbine meter is Fluxi 2000/TZ. Fluxi 2000/TZ is designed to measure natural gas and various non-corrosive gases. This tool can be used to measure low gas flow and high gas flow. This tool can also be used to measure flow under various pressure conditions. Corus is the name of the type of gas volume converter. Corus is one instrument that supports the reading process of various gas meters, and one of them is a gas turbine meter. Corus is designed to achieve high levels of performance and accuracy from robust electronic equipment so that the results of reading the fluid volume available on the gas turbine meter can be calculated more accurately regard to the amount of temperature, pressure and compressibility. The working principle and characteristics of the two instruments make the measurements more accurate.

Keywords : gas turbine meter, fluxi 2000/TZ, gas volume, converter, flow meter
\end{abstract}

\section{INTRODUCTION}

In gas distribution, every industry and household will not be separated from the measurement system that aims to find out how much natural gas has been used. To know this, we need a tool that can read the amount of gas volume used with a good degree of accuracy to avoid the risk of loss and safety of natural gas usage. For this reason, the use of a gas flow meter is necessary. There are several types of gas flow meter can be used in measuring the gas volume. Some types of gas flow meters are gas turbine meter, rotary gas meters and diaphragm gas meters. The primary difference of each type of gas flow meter is the pressure capacity and the speed of the gas flow through it.

Gas flow meter commonly used in industry is gas turbine meter because it has a large capacity. Gas turbine meter is a tool to measure the volume of gas by utilizing the flow rate of gas fluid that drives the turbine wheel. The measurement

Revised Manuscript Received on April 30, 2020.

* Correspondence Author

Fitria Hidayanti*, Engineering Physics Department, Universitas Nasional, Jakarta, Indonesia. Email: fitriahidayanti@gmail.com

(c) The Authors. Published by Blue Eyes Intelligence Engineering and Sciences Publication (BEIESP). This is an open access article under the CC BY-NC-ND license (http://creativecommons.org/licenses/by-nc-nd/4.0/) results of the gas turbine meter will be converted by a gas volume converter or so-called Electronic Volume Converter (EVC) for a more accurate calculation of the volume value taking into account the effects of temperature, pressure and compressibility factor of the gas. The working principle and characteristics of the two instruments make the measurements more accurate.

\section{Natural Gas}

Natural gas is a fossil fuel in the form of gas. Natural gas is a mixture of hydrocarbons which has broad expandability, high compressive strength, low specific gravity and naturally present in the form of gas. In general, natural gas is collected underground with a variety of compositions contained in petroleum content (associated gas). All of the oil content is related to natural gas, where the gas dissolves in crude oil and often forms a "gas cup" above the oil content. In addition, natural gas can also gather at coal mines and natural gas fields [1]. Natural gas is a natural resource with the third-largest reserves in the world after coal and petroleum. Natural gas was not initially consumed as an energy source because of difficulties in transport and so it was always burned when produced together with petroleum. Utilization of natural gas in Indonesia is not only for transportation and households but now for industry. Natural gas in Indonesia has a quite dominant role after the role of oil as the main energy source has begun to be reduced [2].

\section{MATERIALS AND METHOD}

\section{Gas Turbine Meter}

Gas turbine meter is one type of gas flow rate measuring device. Inside gas turbine meter, there are moving parts consisting of a propeller whose rotation speed is proportional to the flow rate through the flow meter. Every time the propeller rotates it produces an electrical pulse at the pickoff mounted on the flow meter casing. These pulses indicate the volume of discrete gas that passes through it. The frequency of the pulses shows the volumetric flow rate and the total accumulation of pulses shows the measured total volume [3]

\section{Gas Turbine Meter Fluxi 2000/TZ}

The type of gas turbine meter is Fluxi 2000 TZ. Fluxi $2000 / \mathrm{TZ}$ is designed to measure natural gas and various non-corrosive gases. This tool can be used to measure low gas flow and high gas flow. This tool can also be used to measure flow under various pressure conditions [4].

\section{Published By:}

Blue Eyes Intelligence Engineering

\& Sciences Publication

DOI: 10.35940/ijmh.H0825.044820

Journal Website: www.ijmh.org 


\section{Working Principle of Gas Turbine Meter Fluxi 2000/TZ and Gas Volume Converter} [5]:

Fluxi 2000/TZ (Fig. 1) consists of five main parts, namely

1. A body that contains all the components;

2. Flow straightener to stabilize and accelerate the flow of gas before the turbine wheel;

3. Measuring units including turbine wheels;

4. Magnetic coupling to transmit the movement of the turbine wheel to the totaliser;

5. A totaliser to display the measured gas.

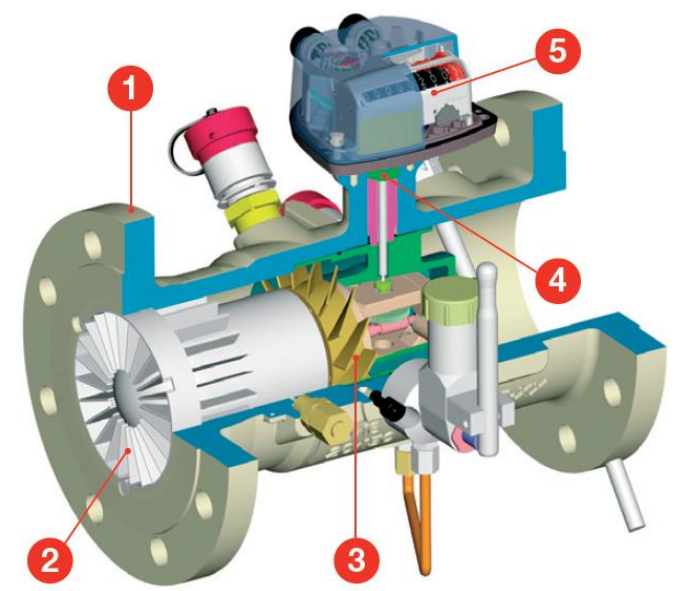

Fig. 1.Gas Turbine Meter Fluxi 2000/TZ [5]

\section{Electronic Volume Converter}

Corus is the name of the type of gas volume converter [4]. Corus is one instrument that supports the reading process of various gas meters, and one of them is a gas turbine meter. Corus shape can be seen in Fig. 2. Corus is designed to achieve high levels of performance and accuracy from robust electronic equipment so that the results of reading the fluid volume available on the gas turbine meter can be calculated more accurately with due regard to the amount of temperature, pressure and compressibility. In distributing data from reading, this tool uses flash memory so that it can store data either per unit day to per month. In the process of transferring reading and calculation data, Corus is also equipped with an infrared sensor that allows Corus users to download new firmware releases via PC or Laptop [5].

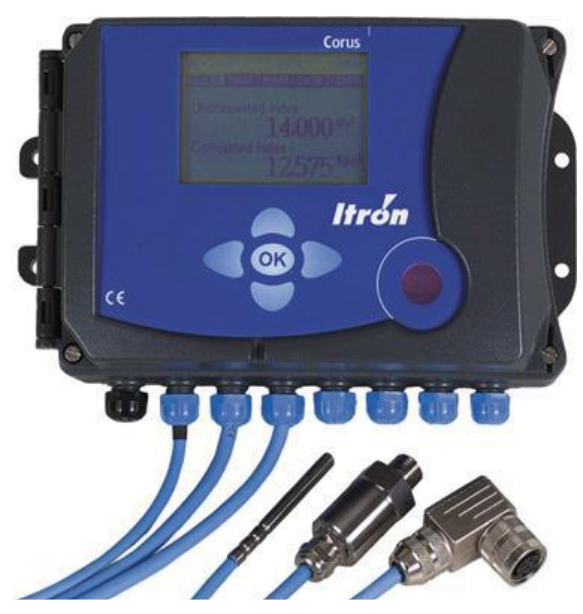

Fig. 2.Electronic Volume Converter Corus [5]

\section{RESULTS AND DISCUSSION}

In the gas turbine meter [6], the flow of gas that has pressure will flow through the gas turbine meter from the inlet to the outlet. The first time, the gas flow will pass through a flow straightener which makes the flow more orderly and the pressure less. After passing through a flow straightener, the gas will flow to the turbine wheel and pass through it to make the turbine wheel move. Thus, the turbine rotational speed is proportional to the rate of the gas flow through it. Turbine wheel rotation will be forwarded to the gear or measuring unit. The measuring unit is connected to a magnetic coupling that functions to transmit the mechanical movement of the measuring unit to the totalizer. Inside the totalizer, some gears move the drum and finally display how much volume of gas passes through the gas turbine meter.

\section{Characteristics of Fluxi 2000 / TZ Gas Turbines Meter}

In this section, we will discuss the features of the Gas Turbine Meter Fluxi 2000/TZ. In its characteristics, there are technical datasheet, pressure loss, dimensions, and size that can be installed on the Gas Turbine Meter Fluxi 2000/TZ. Each turbine size has different characteristics. The characteristics of each size can be known from the datasheet.

Table 1. Rangeability and pulse values [7]

\begin{tabular}{|c|c|c|c|c|c|c|c|c|c|}
\hline G size & $\begin{array}{l}\text { DN } \\
(\mathrm{mm})\end{array}$ & $\begin{array}{l}\text { Max } \\
\text { Flow } \\
\left(m^{3} / h\right)\end{array}$ & $\begin{array}{c}\text { Range- } \\
\text { ability }\end{array}$ & $\begin{array}{c}1 \text { Imp LF\& } \\
\text { Cyble } \\
\left(\mathrm{m}^{3} / \mathrm{mp}\right)\end{array}$ & $\begin{array}{l}\text { Freq LF } \\
\text { Qmax } \\
(\mathbf{H z})\end{array}$ & $\begin{array}{c}\substack{\mathrm{MF} \\
\left(\mathrm{dm}^{2} / \mathrm{mp}\right)} \\
.\end{array}$ & $\begin{array}{l}\text { Freq MF } \\
\text { Qmax } \\
\text { (Hz) }\end{array}$ & $\begin{array}{c}1 \mathrm{Imp} \\
\mathrm{HF2} \\
\left(\mathrm{dm}^{3} / \mathrm{mp}\right)\end{array}$ & $\begin{array}{l}\text { FreqHF2 } \\
\text { Qmax } \\
(\mathrm{Hz})\end{array}$ \\
\hline G65 & 50 & 100 & 20 & 0.1 & 0.28 & 5.8947 & 4.71 & - & - \\
\hline G100 & 80 & 160 & 20 & 1 & 0.04 & 23.07692 & 1.93 & 0.07593 & 585 \\
\hline G160 & & 250 & 20 or 30 & & 0.07 & 23.07692 & 3.01 & 0.07593 & 915 \\
\hline G250 & & 400 & 20 or 30 & & 0.11 & 39.111111 & 2.84 & 0.12869 & 863 \\
\hline G160 & 100 & 250 & 20 & 1 & 0.07 & 23.07692 & 3.01 & 0.06271 & 1107 \\
\hline G250 & & 400 & 20 or 30 & & 0.11 & 23.07692 & 4.81 & 0.06271 & 1772 \\
\hline G400 & & 650 & 20 or 30 & & 0.18 & 39.11111 & 4.62 & 0.10628 & 1699 \\
\hline G400 & 150 & 650 & 20 & 1 & 0.18 & 23.07692 & 7.82 & 0.15385 & 1174 \\
\hline G650 & & 1000 & 20 or 30 & & 0.28 & 23.07692 & 12.04 & 0.15385 & 1806 \\
\hline G1000 & & 1600 & 20 or 30 & & 0.44 & 39.111111 & 11.36 & 0.26074 & 1705 \\
\hline G650 & 200 & 1000 & 20 & 10 & 0.03 & 230.7692 & 1.2 & 0.37661 & 738 \\
\hline G1000 & & 1600 & 20 or 30 & & 0.04 & 230.7692 & 1.93 & 0.37661 & 1180 \\
\hline G1600 & & 2500 & 20 or 30 & & 0.07 & 391.1111 & 1.78 & 0.63829 & 1088 \\
\hline G1000 & 250 & 1600 & 20 & 10 & 0.04 & 230.7692 & 1.93 & 0.5787 & 768 \\
\hline G1600 & & 2500 & 20 or 30 & & 0.07 & 230.7692 & 3.01 & 0.5787 & 1200 \\
\hline G2500 & & 4000 & 20 or 30 & & 0.11 & 391.11111 & 2.84 & 0.9808 & 1133 \\
\hline G1600 & 300 & 2500 & 20 & 10 & 0.07 & 218.1818 & 3.18 & 0.85763 & 810 \\
\hline G2500 & & 4000 & 20 or 30 & & 0.11 & 218.1818 & 5.09 & 0.85763 & 1296 \\
\hline G4000 & & 6500 & 20 or 30 & & 0.18 & 391.11111 & 4.62 & 1.53739 & 1174 \\
\hline G2500 & 400 & 4000 & 20 & 10 & 0.11 & 218.1818 & 5.09 & 2.04673 & 543 \\
\hline G4000 & & 6500 & 20 or 30 & & 0.18 & 218.1818 & 8.28 & 2.04673 & 882 \\
\hline G6500 & & 10000 & 20 or 30 & & 0.28 & 391.1111 & 7.1 & 3.66896 & 757 \\
\hline G4000 & 500 & 6500 & 20 or 30 & 10 & 0.18 & 218.1818 & 8.28 & 2.04673 & 882 \\
\hline G6500 & & 10000 & 20 or 30 & & 0.28 & 391.1111 & 7.1 & 3.66896 & 757 \\
\hline
\end{tabular}

Table 1 displays the range characteristics and pulse values of each turbine size. $G$ size is a measure of the size a gas turbine meter while DN is a measure of a flange of a gas turbine meter.




Table 2. Body materials and approximate weight [7]

\begin{tabular}{|c|c|c|c|c|c|c|c|c|}
\hline $\begin{array}{c}\text { DN } \\
(\mathrm{mm})\end{array}$ & $\begin{array}{l}\text { Length of } \\
\text { body }(\mathrm{mm})\end{array}$ & $\begin{array}{l}\text { ISO } \\
\text { PN 10 }\end{array}$ & $\begin{array}{l}\text { ISO } \\
\text { PN } 16\end{array}$ & $\begin{array}{l}\text { ISO } \\
\text { PN 20 }\end{array}$ & $\begin{array}{c}\text { ISO } \\
\text { PN 25 }\end{array}$ & $\begin{array}{l}\text { IsO } \\
\text { PN 40 }\end{array}$ & $\begin{array}{l}\text { ISO } \\
\text { PN 50 }\end{array}$ & $\begin{array}{l}\text { ISO } \\
\text { PN 110 }\end{array}$ \\
\hline \multirow[t]{2}{*}{50} & 150 & $A^{(n)}$ & $A^{(1)}$ & $A^{(1)} B^{(n)}$ & $A^{(1)}$ & $\mathrm{A}^{(19}$ & $\mathrm{B}^{2}$ & $\mathrm{~B}^{\mathrm{A}}$ \\
\hline & & 8 & 8 & 8 & 8 & 8 & 11 & 11 \\
\hline \multirow[t]{2}{*}{80} & 240 & $A c$ & $A c$ & $A B$ & $A c$ & Ac & B & B \\
\hline & & 19 & 19 & 19 & 19 & 19 & 30 & 37 \\
\hline \multirow[t]{2}{*}{100} & 300 & $A c$ & $A c$ & AB & B & B & B & B \\
\hline & & 22 & 22 & 22 & 25 & 25 & 45 & 55 \\
\hline \multirow[t]{2}{*}{150} & 335 & $A^{*}$ a & $A(A)$ & $A($ a) & & & & \\
\hline & & 46 & 46 & 46 & & & & \\
\hline \multirow[t]{2}{*}{150} & 450 & $A B$ & $A B$ & $A B$ & B & B & B & B \\
\hline & & 54 & 54 & 54 & 54 & 54 & 80 & 95 \\
\hline \multirow[t]{2}{*}{200} & 600 & $A_{C}$ & Ac & $A B$ & B & B & $\mathrm{B}^{1 / 9}$ & $B^{19}$ \\
\hline & & 83 & 83 & 83 & 83 & 110 & 130 & 150 \\
\hline \multirow[t]{2}{*}{250} & 750 & B & B & B & B & B & $B^{n}$ & $\mathrm{~B}^{\mathrm{m} 9}$ \\
\hline & & 120 & 120 & 120 & 120 & 140 & 220 & 245 \\
\hline \multirow[t]{2}{*}{300} & 900 & B & B & B & B & B & $\mathrm{B}^{n}$ & $\mathrm{~B}^{\mathrm{n}}$ \\
\hline & & 190 & 190 & 190 & 190 & 220 & 265 & 265 \\
\hline \multirow[t]{2}{*}{400} & 1200 & B & B & B & B & B & $\mathrm{B}^{\mathrm{m}}$ & $\mathrm{B}^{(n)}$ \\
\hline & & 440 & 440 & 440 & 440 & 490 & 680 & 740 \\
\hline \multirow[t]{2}{*}{500} & 1500 & B & B & B & B & B & $B^{n}$ & $B^{n}$ \\
\hline & & 580 & 580 & 580 & 580 & 640 & 770 & 950 \\
\hline \multicolumn{5}{|c|}{$\begin{array}{l}\text { A: Ductile iron EN-GISS-400-18LT } \\
\text { B: Steel (Cast steel GS or welded steel) } \\
\text { c: Cast steel GS with minimum ordering quantity }\end{array}$} & \multicolumn{4}{|c|}{$\begin{array}{l}\text { (1) HF2 not available, } 1 \text { thermowell only } \\
\text { (2) HF2 not available } \\
\text { (1) HF2 and thermowells not available }\end{array}$} \\
\hline
\end{tabular}

Table 2 showed that the material characteristics and average weight of the gas turbine meter Fluxi 2000/TZ, the flange has different constituent materials.

\section{Electronic Volume Converter}

Electronic Volume Converter (EVC) Corus is connected to several transmitters such as pressure transmitters, temperature transmitters and LF/MF/HF transmitters that are mounted on a turbine flow meter. This temperature sensor has an IP67 protection level in accordance with EN 60529 and with a cable length of $2.50 \mathrm{~m}$ or $0.80 \mathrm{~m}$. The $\mathrm{Pb}$ reference pressure and $\mathrm{Tb}$ reference temperature must be programmed into the device. Corus measures the volume of the gas under measurement conditions (Vm), under specific pressure (Pm) and temperature conditions (Tm).

The results of gas volume conversion will be displayed on the Corus screen. Each measurement result can also be stored in flash memory. An example of the Corus screen display can be seen in Fig. 3. There are two types of gas volumes: the gas volume calculated by the LF / MF / HF transmitter (not yet converted) and the volume of the gas that has been calculated taking into account the pressure, temperature, and compressibility factor (converted).

\begin{tabular}{|l|}
\hline INDEX \\
\hline UnConve $\mid$ ALARM DATA CONFI \\
$00012345.000 \mathrm{~m} 3$ \\
Converted index: \\
$00054321.100 \mathrm{Nm} 3$ \\
\hline
\end{tabular}

Fig. 3.Electronic Volume Converter Corus Display

The Corus characteristic is that the Corus cover is made of polycarbonate material and the dimensions of this tool are $22.2 \times 14.5 \times 8.6\left(\mathrm{~cm}^{3}\right)$ with a weight of about $1.5 \mathrm{~kg}$. Corus shows there are five keyboards to operate Corus and one screen, in addition to that there is also an infrared sensor downloading the new firmware release via PC. Corus has IP65 protection in accordance with EN60529 standard. The Corus reference conditions for pressure are in the range of 0.9 to 2 bar, whereas for temperatures in the range of $0-40{ }^{\circ} \mathrm{C}$. Corus has standard RS232 \& Optical communication ports and as an option can use RS485-PSTN Modem. Corus input volume is Low Frequency (LF) type connected to flow meter with a maximum of $2 \mathrm{~Hz}$. Corus power supply can be an internal battery (16.5 A.h) or an external DC voltage.

\section{CONCLUSION}

Gas turbine meter is a flow meter or device that measures the gas volume based on the speed of the gas flow that drives the turbine wheel. The magnitude of the flow rate is proportional to the turbine wheel's rotation speed. The working principle of the Gas Turbine Meter, the flow of gas that has pressure will flow through the gas turbine meter from the inlet to the outlet. The first time, the gas flow will pass through a flow straightener which makes the flow more orderly and the pressure less. After passing through a flow straightener, the gas will flow to the turbine wheel and pass through it so as to make the turbine wheel move. Thus, the turbine rotational speed is proportional to the rate of the gas flow through it. Turbine wheel rotation will be forwarded to the gear or measuring unit. The measuring unit is connected to a magnetic coupling that functions to transmit the mechanical movement of the measuring unit to the totalizer. Inside the totalizer, some gears move the drum and finally display how much volume of gas passes through the gas turbine meter. Corus is a gas volume converter. This tool is designed to calculate the volume of gas based on several quantities, namely the volume under measurement conditions, temperature, pressure and compressibility factors. EVC Corus will measure the volume of gas under measurement conditions (Vm), under specific pressure (Pm) and temperature conditions (Tm). This volume is converted to volume on a basic condition by Corus. The characteristics of the gas meter and EVC turbine are in the datasheet. Each size of the gas turbine meter and EVC has a different performance. So that in applying and choosing the size of the gas turbine meter can be seen through the characteristics of the tool.

\section{ACKNOWLEDGMENT}

Thank you for Lembaga Penelitian dan Pengabdian kepada Masyarakat (LPPM) Universitas Nasional and my collegues in Faculty of Engineering and Science, Universitas Nasional.

\section{REFERENCES}

1. Speight, J.G., Natural gas: a basic handbook. 2018: Gulf Professional Publishing.

2. Prabowo, H., T. Sumartono, and B. Saputra, The Conversion of LPG Gas to Natural Gas: Study about Government Policy of Natural Gas Conversion in Indonesia. International Journal on Language, Research and Education Studies, 2020. 4(1): p. 118-135.

3. Tillery, S.W. and J.N. Cook, Gas turbine fuel flow measurement using inert gas. 2017, Google Patents.

4. Chung, H. S. H., Wang, H., Blaabjerg, F., \& Pecht, M. Reliability of power electronic converter systems. 2015: Institution of Engineering and Technology.

5. Itron, "GAS BOOK Metering \& Systems," Honeywell Gasb., pp. 18-19, 2013.

6 Hidayanti F., Sudrajat A., Warih, G. F. H., Frequency Control System Design of Turbine Gas using Electro-Hydraulic Converter. 2020. International Journal of Innovative Technology and Exploring Engineering (IJITEE). 9(6) p. 620-625.

7. T. G. Meter, "Fluxi 2000/TZ," 2000.

Published By:

Blue Eyes Intelligence Engineering

\& Sciences Publication

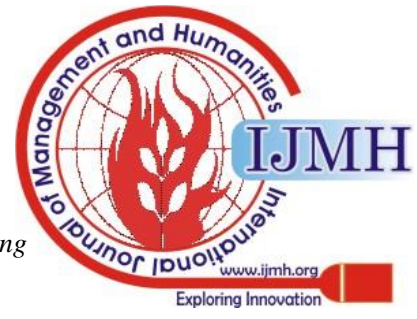


Working Principle of Gas Turbine Meter Fluxi 2000/TZ and Gas Volume Converter

\section{AUTHORS PROFILE}

Fitria Hidayanti, Ph.D. candidate at Faculty of Engineering, University of Indonesia. She obtained her bachelor degree at Bandung Institute of

Technology, Indonesia and master degree at University of Indonesia. Currently. She is an Assistant Professor at Engineering Physics Department, Universitas Nasional, Jakarta, Indonesia.

Haura Ishthafayna, She obtained Bachelor Degree at Engineering Physics Department, Universitas Nasional, Jakarta, Indonesia. 